\title{
Quantification of Amiridine in Human Plasma by High-Performance Liquid Chromatography Coupled with Electrospray Tandem Mass Spectrometry
}

\author{
Igor I. Miroshnichenko and Angelina I. Platova \\ Mental Health Research Center of RAMS, Moscow 115522, Russia \\ Correspondence should be addressed to Angelina I. Platova; platova6283@mail.ru
}

Received 9 April 2013; Revised 3 July 2013; Accepted 17 July 2013

Academic Editor: Irene Panderi

Copyright (C) 2013 I. I. Miroshnichenko and A. I. Platova. This is an open access article distributed under the Creative Commons Attribution License, which permits unrestricted use, distribution, and reproduction in any medium, provided the original work is properly cited.

\begin{abstract}
The aim of this study was to develop and validate a high-performance liquid chromatographic-tandem mass spectrometric (LCMS/MS) method for analysis of the amiridine in human plasma. The analyte and internal standard (IS), zolpidem, were extracted from human plasma by solid phase extraction (SPE with SOLA cartridges) and separated on a Zorbax SB-C18 column using methanol and $0.2 \%$ formic acid in water as mobile phase. Detection was performed using an electrospray ionization source and mass spectrometric positive multireaction monitoring mode $(+\mathrm{MRM})$ at a voltage capillary of $+2000 \mathrm{~V}$. The assay was linear over the concentration range $0.5-200 \mathrm{ng} / \mathrm{mL}$ with the lowest limit of quantification (LLOQ) of $0.5 \mathrm{ng} / \mathrm{mL}$. The method also afforded satisfactory results in terms of the sensitivity, specificity, precision (intra- and interday CV $<12 \%$ ), accuracy, recovery, and the stability of the analyte under various conditions. The method can be successfully applied to pharmacokinetic studies.
\end{abstract}

\section{Introduction}

Alzheimer's disease $(\mathrm{AD})$ is a devastating disease that results in the deterioration of memory, cognitive function, and the ability to care for oneself. $\mathrm{AD}$, the most prevalent form of dementia, accounts for 50 to 70 percent of dementia cases and significantly impacts patients, families, caregivers, communities, and society as a whole $[1,2]$. One of the most popular therapeutic strategies in $\mathrm{AD}$ is the control of cholinergic neurotransmission by the slow decline of neuronal degeneration or increasing cholinergic transmission [3]. Cholinesterase inhibitors are the mainstay treatment, yet they provide only limited and transient improvement in AD [1].

Amiridine (ipidacrine, neuromidin), 9-amino-2,3,5,6,7,8hexahydro-H-cyclopenta[b]quinoline is a nonselective inhibitor of acetylcholinesterase and butyrylcholinesterase $[4,5]$. The chemical structure of amiridine as shown in Figure 1 [6]. This circumstance stipulated using amiridine for the treatment of patients with mixed vascular and Alzheimer's dementia of mild and moderate severity [7].
Appropriate analytical method is an urgent need to study amiridine's pharmacokinetic properties. The HPLCUV approach for content determination has been applied to a preclinic investigation of amiridine [8]. Unfortunately, this method was not sensitive enough for human pharmacokinetic studies of amiridine. LC/MS spectrometry based techniques are now the mainstay for such pharmacokinetic studies because of sensitivity, selectivity, speed, and cost effectiveness [9]. HPLC-MS/MS method for quantification of tacrine in biological samples has been developed [10]. However, we do not find HPLC-MS/MS methods reported in the literature for quantification of amiridine in biological samples.

The most commonly used sample preparation methods for blood plasma samples are liquid-liquid extraction (LLE) and solid-phase extraction (SPE). SPE is growing in use, and it offers certain advantages over LLE, including better specificity, the ability to obtain cleaner samples, good reproducibility, and a substantial reduction in the volume of solvent required [11]. 


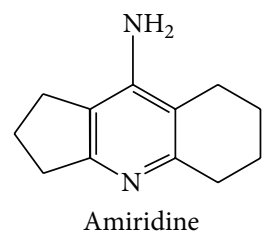

FIGURE 1: Chemical structure of amiridine.

This paper reports on a rapid and sensitive LC-MS/MS method for the determination of amiridine in human plasma using SOLA cartridges. SOLA combines polyethylene frit materials and stationary phase components into one uniform entity. As a result, these cartridges deliver superior reproducibility, recovery, and sensitivity and reduce the levels of contaminants within the sample eluate. The method employs using zolpidem as internal standard and is completed in a run time of only $4 \mathrm{~min}$.

\section{Experimental}

2.1. Chemicals and Reagents. Amiridine and zolpidem (internal standard, IS) were presented from (the Mental Health Research Center of RAMS, Moscow, Russia). Formic acid and methanol were of HPLC-grade. Deionized water was prepared from distilled water using Simplicity UV System (Millipore, USA). All other chemicals and solvents were of analytical grade and used as received.

2.2. LC-MS/MS Conditions. The HPLC-MS/MS system consisted of an Agilent 1200 series binary pump, an auto sampler connected to Agilent 6410-2K Triple Quad LC-MS (Agilent Technologies, Palo Alto, CA, USA) using a electrospray ionization source. The instrument was interfaced to a computer running Agilent MassHunter B.01.04 software.

Amiridine and IS were separated on a Zorbax SB-C18 column $(3.5 \mu \mathrm{m}, 100 \mathrm{~mm} \times 4.6 \mathrm{~mm}$ I.D., Agilent, USA $)$ through a $12.5 \mathrm{~mm} \times 4.6 \mathrm{~mm}$ precolumn, both maintained at $21^{\circ} \mathrm{C}$. The mobile phase consisted of acetonitrile- $0.2 \%$ water solution of formic acid $(50: 50, \mathrm{v} / \mathrm{v})$. The flow rate throughout the chromatographic analysis was $0.5 \mathrm{~mL} / \mathrm{min}$, and the total run time was 4 minutes. The injection volume was $5 \mu \mathrm{L}$. The retention times were $2.7 \mathrm{~min}$ for amiridine and $3.45 \mathrm{~min}$ for IS.

The detector was operated at unit resolution in the positive multiple-reaction monitoring ( + MRM) mode using the transitions of the protonated molecular ions of amiridine $(189.1 \rightarrow 161.1 \mathrm{~m} / z)$ and IS $(308.2 \rightarrow 235.1 \mathrm{~m} / z)$. MS parameters were optimized by a syringe pump infusion of standard solution containing analyte and IS. The capillary voltage was set at $2000 \mathrm{~V}$, and corona current was set at $4 \mu \mathrm{A}$. Nitrogen was used as nebulizer gas, and pressure was set at 60 p.s.i. Desolvation gas (nitrogen) was heated to $300^{\circ} \mathrm{C}$ and delivered at a flow rate of $5 \mathrm{~L} / \mathrm{min}$. For collision-induced dissociation (CID), high purity nitrogen was used at a pressure of $0.15 \mathrm{MPa}$. During the data acquisition, dwell time was $200 \mathrm{~ms}$. The fragmentation energy of Q1 and collision energy were $135 \mathrm{~V}$ and $56 \mathrm{~V}$ for amiridine and $30 \mathrm{~V}$ and $39 \mathrm{~V}$ for IS, respectively.

2.3. Preparation of Calibration Standards and Quality Control Samples. A stock solution of amiridine was prepared in methanol at a concentration of $1.0 \mathrm{mg} / \mathrm{mL}$. Standard solutions $(0.5,1,5,10,50,100$, and $200 \mathrm{ng} / \mathrm{mL})$ were prepared by serial dilution of the stock solution with methanol. Low, medium, and high concentration quality control (QC) solutions $(2.5,25$, and $110 \mathrm{ng} / \mathrm{mL})$ were prepared in the similar way. The stock solution of IS $(1.0 \mathrm{mg} / \mathrm{mL})$ was also prepared in methanol and then diluted with methanol to a final concentration of $100 \mathrm{ng} / \mathrm{mL}$. All solutions were stored at $4^{\circ} \mathrm{C}$ and used within one month after preparation. Calibration standards and QC samples were prepared by adding $50 \mu \mathrm{L}$ standard or QC and $50 \mu \mathrm{L}$ IS solution to $500 \mu \mathrm{L}$ blank human plasma.

2.4. Sample Preparation. A sample $(500 \mu \mathrm{L})$ of human plasma was transferred to a $5.0 \mathrm{~mL}$ glass tube, $50 \mu \mathrm{L}$ methanol or $50 \mu \mathrm{L}$ standard of amiridine and $50 \mu \mathrm{L}$ IS solutions were added. If needed (sample not transparent), the mixture was ultrasonicated. SPE was conducted by using SOLA RP extraction cartridges. The cartridges were conditioned sequentially with $500 \mu \mathrm{L}$ of methanol and with $500 \mu \mathrm{L}$ of water, and $500 \mu \mathrm{L}$ of plasma sample diluted equal volume of water was then loaded. The loaded cartridges were washed with $500 \mu \mathrm{L}$ $5 \%$ methanol in water, and subsequently the analyte was eluted with methanol. The elution was then evaporated to dryness under $\mathrm{N} 2$ stream at $50^{\circ} \mathrm{C}$, reconstituted with $200 \mu \mathrm{L}$ of HPLC mobile phase, and vortex mixed for $10 \mathrm{~s}$. Finally, the solution was transferred to the autosampler vials, and $5 \mu \mathrm{L}$ was injected into HPLC-MS/MS system.

2.5. Method Validation. The method validation assays were carried out according to the currently accepted US Food and Drug Administration (FDA) and guidelines in Peters et al. [12]. The method's specificity was tested by screening six different batches of healthy human blank plasma. Each blank sample was tested for interference using the proposed extraction procedure and chromatographic/spectroscopic conditions and compared with those obtained with an aqueous solution of the analyte at a concentration near to the LLOQ.

The matrix effect on the ionization of analytes was evaluated by comparing the peak area of analytes resolved in blank sample (the final solution of blank plasma after extraction and reconstitution) with that resolved in mobile phase.

Three different concentration levels of amiridine $(2.5,25$, and $110 \mathrm{ng} / \mathrm{mL}$ ) were evaluated by analyzing five samples at each level. The blank plasma used in this study were five different batches of healthy human blank plasma. If the ratio was $<85$ or $>115 \%$, an exogenous matrix effect was implied.

Linearity was tested for the range of concentrations 0.5-200 ng/mL. For the determination of linearity, standard calibration curves of seven points (nonzero standards) were used. In addition, a blank plasma sample were also analyzed to confirm absence of interferences, these sample was not 


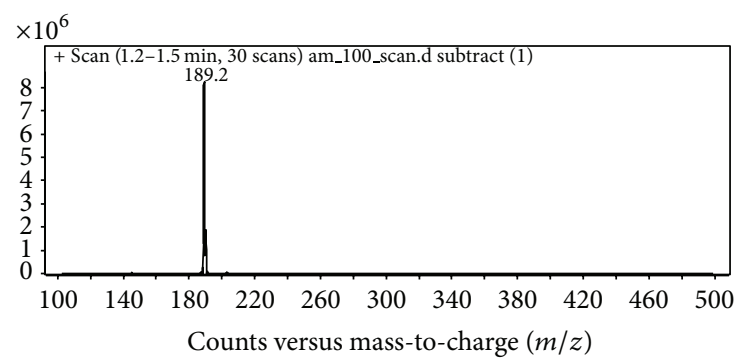

FIGURE 2: Fullscan positive ion turboIonspray Q1 mass spectra of amiridine.

used to construct the calibration function. The standard calibration curves were constructed using the peak area ratios of amiridine and IS versus amiridine nominal concentrations.

The intraday precision and accuracy of the assay were measured by analyzing five spiked samples of amiridine at each QC level $(2.5,25$ and $110 \mathrm{ng} / \mathrm{mL})$. The interday precision and accuracy were determined over three consecutive days by analyzing 15 QC samples. The acceptance criteria for precision and accuracy deviation values should be within $15 \%$ of the actual values.

The extraction yield (or absolute recovery) of amiridine was determined by comparing the mean peak area of extracted low, medium, and high $(2.5,25$, and $110 \mathrm{ng} / \mathrm{mL})$ quality control samples to the mean peak area of methanol standards with the same concentrations.

For sensitivity determination, the LLOQ was defined as the lowest concentration in the calibration curve at which both precision and accuracy were less than or equal to $20 \%$, and signal $/$ noise $(S / N)>10$. The $0.5 \mathrm{ng} / \mathrm{mL}$ concentration was investigated as the lower limit of quantification. Reproducibility and precision were also determined.

To evaluate stability on repeat analysis of samples, freezethaw stability was determined for three concentrations of amiridine in plasma. QC plasma samples were tested after three freeze $\left(-20^{\circ} \mathrm{C}\right)$ and thaw (room temperature) cycles.

\section{Results and Discussion}

3.1. LC-MS/MS Conditions. The LC-MS/MS operation parameters for the determination of amiridine and IS were carefully optimized. Zolpidem was selected as the IS, because its chromatographic behavior and extraction efficiency were similar to those of analyte. All authentic amiridine and zolpidem standard solutions were first scanned from $\mathrm{m} / \mathrm{z} 100$ to 500 in ESI positive mode to identify the abundance of ions corresponding to the respective drugs. Both analyte and IS responded best to the positive ionization mode, with the protonated molecular ions $[\mathrm{M}+\mathrm{H}]^{+}$as the major species. Full scan ion spectra of amiridine was shown in Figure 2. The MRM acquisitions were performed at unit resolution using the transition $189.1 \rightarrow 161.1 \mathrm{~m} / z$ for amiridine and $308.2 \rightarrow$ $235.1 \mathrm{~m} / z$ for IS, respectively. The transition $189.1 \rightarrow 161.1$ $\mathrm{m} / \mathrm{z}$ was used for quantification of amiridine because of its stabilized ions response and no endogenous interference. The

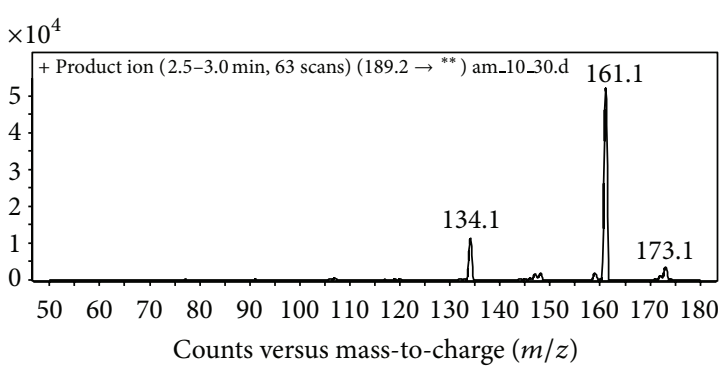

FIGURE 3: MS/MS spectrum of the $m / z=189.1$ parent ion, exhibiting the product ions of amiridine at $\mathrm{m} / z=161.1$.

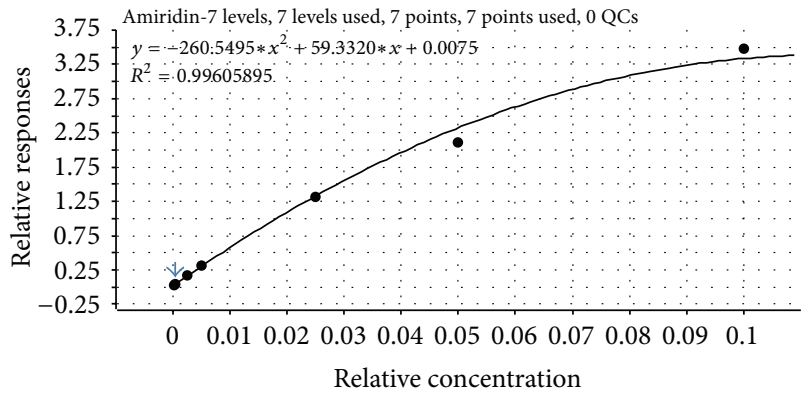

FIgURE 4: Regression line for the determination of amiridine in human plasma.

mass parameters were optimized by observing the maximum response obtained for the product ions. The intensities of its protonated molecules were compared at fragmentor voltages of $90,100,120,130,135,140$, and $150 \mathrm{~V}$ in order to determine the optimal collision energy. The results showed that the highest sensitivities could be obtained by using a $135 \mathrm{~V}$ fragmentor voltage. The fragment ion at $m / z$ 161.1, which was chosen for the MRM acquisition, proved to be steady and abundant with collision energy of $30 \mathrm{~V}$. The MS2 mass spectra of amiridine is shown in Figure 3.

Furthermore, the mobile phase system was optimized through several trials to achieve satisfactory chromatographic behavior and the ionization responses of amiridine and IS. The ionization of amiridine and IS was affected by the composition of mobile phase. In the preliminary experiments, methanol, acetonitrile, ammonium acetate, and formic acid in various proportions were tested. Acetonitrile, rather than methanol, was chosen as the organic modifier because it leads to the good peak shape of amiridine and satisfactory retention time. When ammonium acetate was added in the mobile phase, the response of the analyte was distinctly decreased. Both the analyte and IS were found to have higher response and better peak shapes in the mobile phase containing $0.2 \%$ formic acid. Finally, in terms of peak shape, retention time, and sensitivity, we employed acetonitrile-water $0.2 \%$ formic acid $(50: 50, \mathrm{v} / \mathrm{v})$, as the mobile phase.

3.2. Assay Validation. The data points of the standards in the ranges of $0.5-200 \mathrm{ng} / \mathrm{mL}$ (Figure 4) used to create a calibration curve, when graphed, fit perfectly on a second 
TABLE 1: Accuracy and precision of the assay for determination of amiridine in plasma $(n=5)$.

\begin{tabular}{lcccccc}
\hline $\begin{array}{l}\text { Added to } \\
\text { plasma }(\mathrm{ng} / \mathrm{mL})\end{array}$ & $\begin{array}{c}\text { Intraassay } \\
\text { Measured } \\
\text { concentration }\end{array}$ & $\begin{array}{c}\text { Accuracy } \\
\%\end{array}$ & $\begin{array}{c}\text { Precision } \\
\text { CV }\end{array}$ & $\begin{array}{c}\text { Measured } \\
\text { concentration }\end{array}$ & $\begin{array}{c}\text { Accuracy } \\
\%\end{array}$ & $\begin{array}{c}\text { Precision } \\
\text { CV }\end{array}$ \\
\hline 2.5 & 2.72 & 8.88 & 10.08 & 2.61 & 4.44 & 11.93 \\
25 & 26.03 & 4.12 & 8.33 & 26.48 & 5.92 & 7.12 \\
110 & 108.31 & -1.5 & 4.02 & 106.13 & -3.5 & 5.11 \\
\hline
\end{tabular}

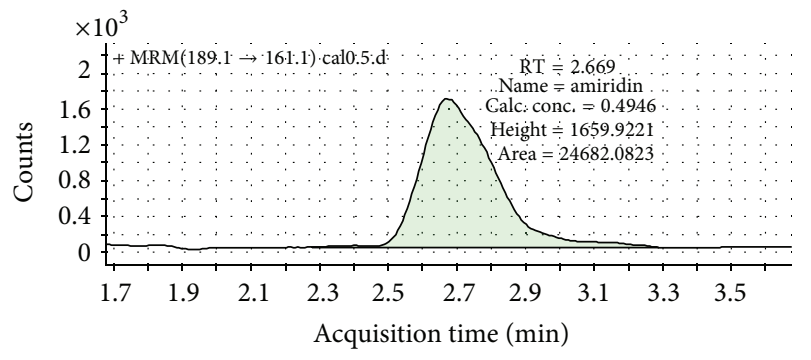

FIGURE 5: MRM mass chromatograms of LLOQ $(0.5 \mathrm{ng} / \mathrm{mL})$ of amiridine.

order polynomial curve: $Y=0.0075+0.0297 * X-6.514 E^{-5} *$ $X^{2}$, with a coefficient of correlation $(r)$ of 0.996 (where $Y-$ the ratio of the peak areas of amiridine to the peak area of the internal standard; $X$-amiridine concentration, $\mathrm{ng} / \mathrm{mL}$ ). On the other hand, calibration curve shows good linearity with $\mathrm{ULOQ}=100 \mathrm{ng} / \mathrm{m}$. The regression equation for the calibration plot was $y=0.016+0.023 * x$, with a coefficient of correlation $(r)$ of 0.995 .

LLOQ for amiridine in plasma was proved to be $0.5 \mathrm{ng} / \mathrm{mL}(S / N=23.5)$ (Figure 5).

In terms of matrix effects, the ratios of the peak responses for amiridine were $97.3 \%, 98.1 \%$, and $97.2 \%$ at $2.5,25$, and $110 \mathrm{ng} / \mathrm{mL}$, respectively. The results indicated that coeluting endogenous substances hardly inhibited the ionization of amiridine, and the ion suppression from rat plasma matrix was consistent for this analytical method and would not interfere with the measurement of amiridine. The extraction recovery determined for amiridine was shown to be consistent, precise, and reproducible. The absolute recoveries of amiridine from the rat plasma at the three concentrations were about $87 \%$.

The intraday (Figure 6) and interday precisions (CV, $n=$ 5) for amiridine were satisfactory at the three concentrations studied. Data on precision and accuracy are shown in Table 1. The results of freeze-thaw stability indicated that the analyte is stable in plasma for three freeze-thaw cycles, when stored at $-20^{\circ} \mathrm{C}$ and thawed to room temperature. Long-term stability indicates that storage of amiridine plasma samples at $-20^{\circ} \mathrm{C}$ is adequate when stored for 30 days, and no stability related problems would be expected during routine analysis for the pharmacokinetic, bioavailability, or bioequivalence studies.

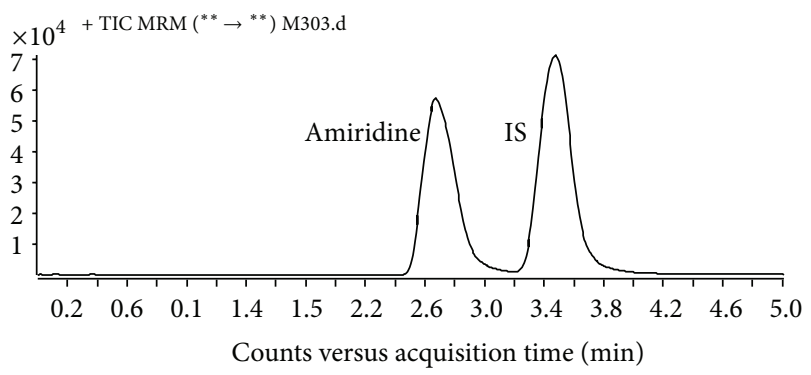

FIGURE 6: Typical mass chromatograms of plasma QC sample spiked with amiridine $(25 \mathrm{ng} / \mathrm{mL})$ and the IS $(100 \mathrm{ng} / \mathrm{mL})$, validation of amiridine quantitation.

\section{Conclusion}

The proposed method of analysis provided a sensitive and specific assay for amiridine determination in human plasma. No significant interference caused by endogenous compounds was observed. The method was rapid, selective, and highly sensitive with a LLOQ of $0.5 \mathrm{ng} / \mathrm{mL}$ for amiridine. Simple SPE procedure and short run time can provide a short analysis time that is important for large sample batches. It was shown that this method is suitable for the analysis of amiridine in plasma samples collected for pharmacokinetic, bioavailability, or bioequivalence studies.

\section{Conflict of Interests}

The authors confirm that they have no conflict of interests.

\section{References}

[1] P. M. Kidd, "Alzheimer's disease, amnestic mild cognitive impairment, and age-associated memory impairment: current understanding and progress toward integrative prevention," Alternative Medicine Review, vol. 13, no. 2, pp. 85-115, 2008.

[2] H. W. Querfurth and F. M. LaFerla, "Alzheimer's disease," New England Journal of Medicine, vol. 362, no. 4, pp. 329-344, 2010.

[3] M. T. Beier, "Treatment strategies for the behavioral symptoms of Alzheimer's disease: focus on early pharmacologic intervention," Pharmacotherapy, vol. 27, no. 3, pp. 399-411, 2007.

[4] Y. Burov, L. Cadysheva, T. Rodakidze, E. Peganov, A. Voronin, and H. Parvez, "Pharmacological effects of amiridin," European Journal of Pharmacology, vol. 183, no. 4, p. 1464, 1990. 
[5] J. Kojima, K. Onodera, M. Ozeki, and K. Nakayama, "Ipidacrine (NIK-247): a review of multiple mechanisms as an antidementia agent," CNS Drug Reviews, vol. 4, no. 3, pp. 247-259, 1998.

[6] R. A. De Aquino, L. V. Modolo, R. B. Alves, and A. de Fátima, "Design of new drugs for the treatment of Alzheimers disease based on tacrine structure," Curr Drug Targets, vol. 14, no. 3, pp. 378-397, 2013.

[7] I. V. Damulin, D. A. Stepkina, and A. B. Lokshina, "Neyromidin in mixed vascular and Alzheimer's dementia," Zhurnal Nevrologii i Psihiatrii imeni S.S. Korsakova, vol. 111, no. 2, pp. 40-43, 2011.

[8] I. Miroshnichenko, Neurochemical and pharmacokinetic aspects of mechanism of action for drugs with nootropic and antiamnestic activities [Ph.D. thesis], 1995, Doctor of Science and Pharmacology.

[9] M. Niwa, "Chemical derivatization as a tool for optimizing MS response in sensitive LC-MS/MS bioanalysis and its role in pharmacokinetic studies," Bioanalysis, vol. 4, no. 2, pp. 213-220, 2012.

[10] Z. Li, Y. Hua, L. W. Ming et al., "Selective and sensitive determination of bis(7)-tacrine, a high erythrocyte binding acetylcholinesterase inhibitor, in rat plasma by high-performance liquid chromatography-tandem mass spectrometry," Biomedical Chromatography, vol. 22, no. 4, pp. 414-420, 2008.

[11] K. Meadows, T. Liddicoat, and M. Oliver, "Revolutionizing SPE for improved bioanalysis," Bioanalysis, vol. 4, no. 22, pp. 26612663, 2012.

[12] F. T. Peters, O. H. Drummer, and F. Musshoff, "Validation of new methods," Forensic Science International, vol. 165, no. 2-3, pp. 216-224, 2007. 

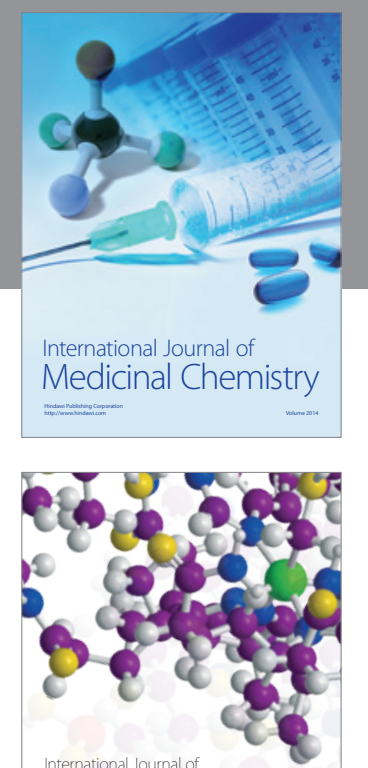

\section{Carbohydrate} Chemistry

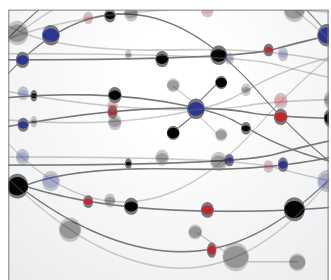

The Scientific World Journal
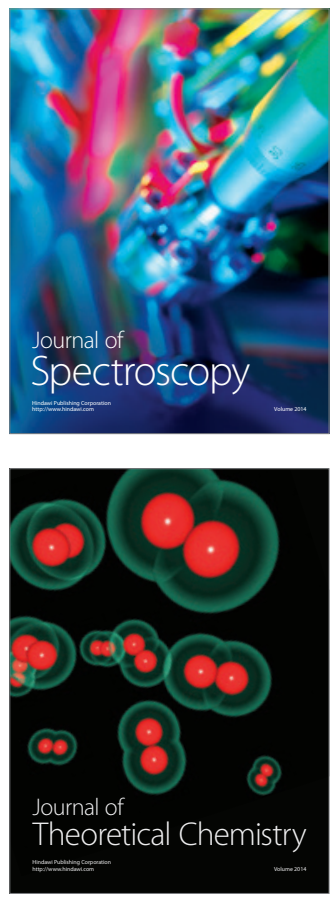
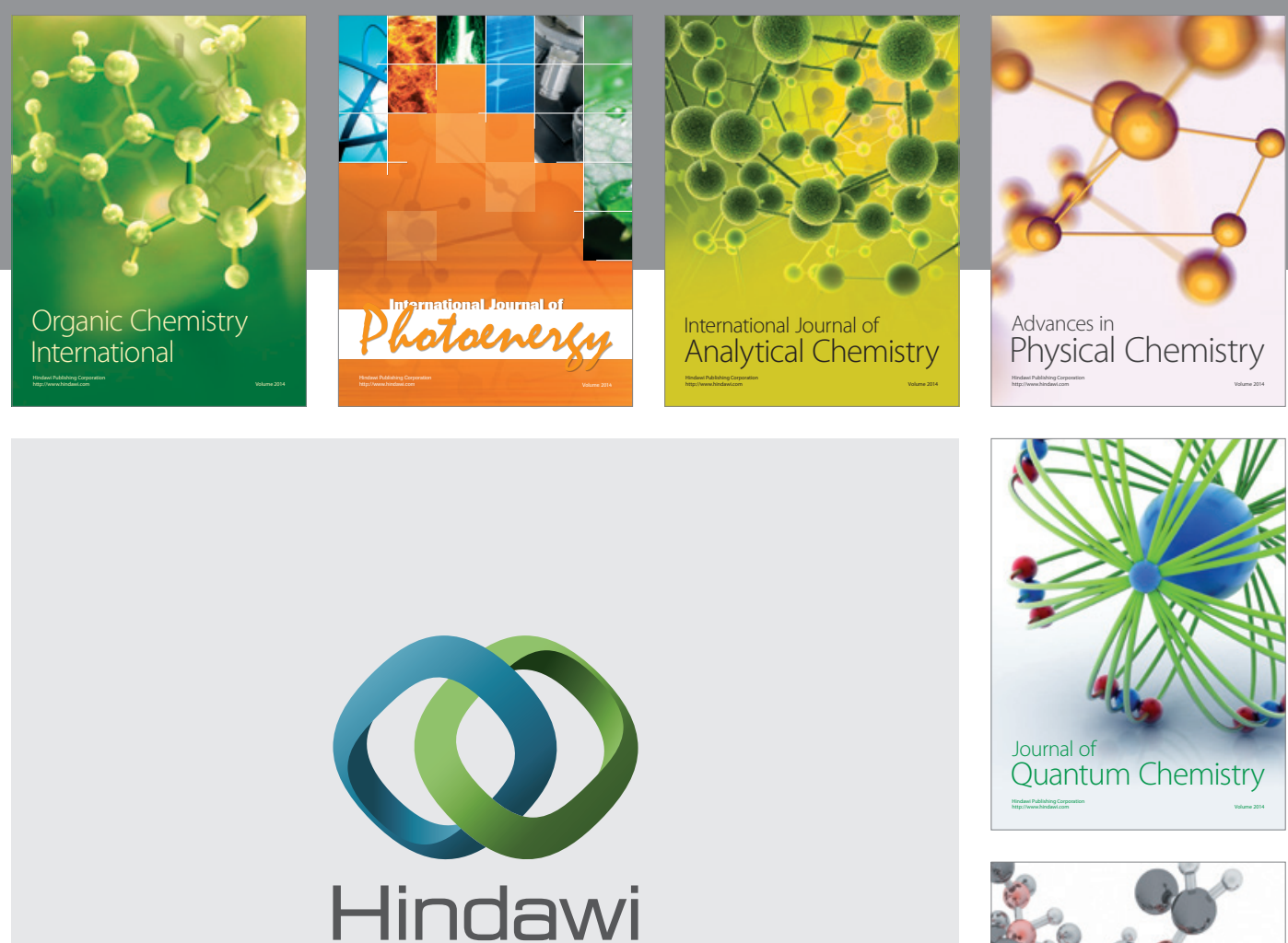

Submit your manuscripts at

http://www.hindawi.com

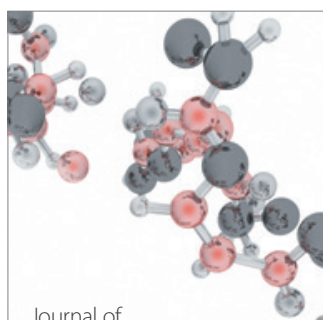

Analytical Methods

in Chemistry

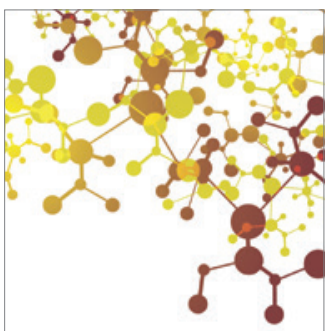

Journal of

Applied Chemistry

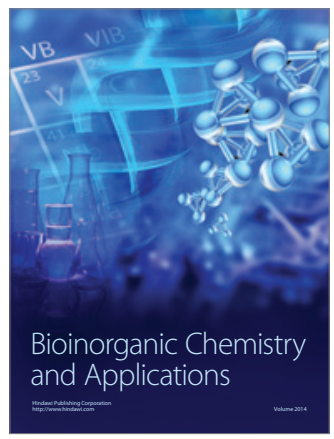

Inorganic Chemistry
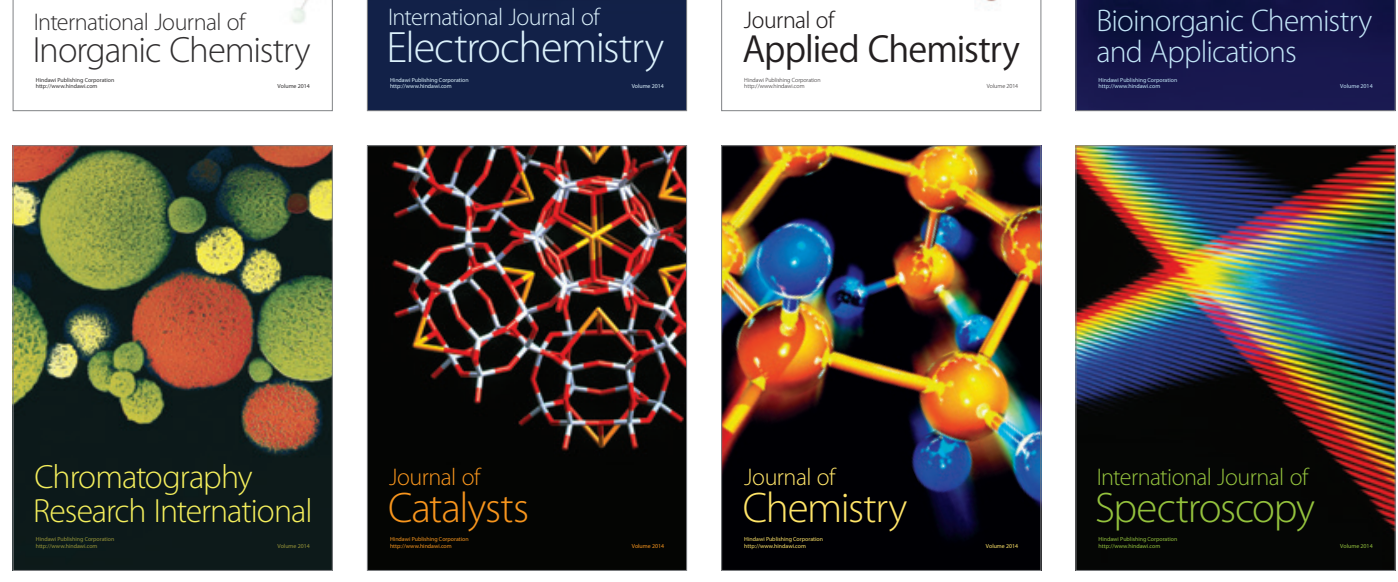